\title{
PERCEPÇÕES DOS MORADORES DO BAIRRO DA ENGOMADEIRA SOBRE UNEB-BA
}

\author{
José Ricardo Rosa dos Santos ${ }^{1}$; https://orcid.org/0000-0003-0432-7089 \\ Jeanne Lopes Santana²; https://orcid.org/0000-0002-6425-1584 \\ Luís Geraldo Leão Guimarães ${ }^{3}$; https://orcid.org/0000-0003-1488-4145 \\ Natanael Reis Bomfim ${ }^{4}$; https://orcid.org/0000-0002-5122-9820
}

\begin{abstract}
Resumo
Este trabalho tem como objetivo analisar as percepções dos moradores do Bairro Engomadeira sobre a Universidade do Estado da Bahia (UNEB), Campus I, Salvador, para assim propor melhorias nas relações estabelecidas entre a Comunidade e a Universidade. Para a discussão, utilizaram-se autores como Fialho, Midlej e Santos. A pesquisa foi desenvolvida numa abordagem qualitativa, utilizando como instrumento de coleta de dados a entrevista semiestruturada e questionários fechados, aplicados em amostra não probabilística de 20 (vinte) moradores, dividindo-se em três grupos, por escolaridade: nível fundamental, nível médio e nível superior, para identificar e analisar as suas percepções. Recorreu-se à análise de conteúdo de Bardin (2002) e à luz de autores como Midlej e Santos, para tratamento dos dados coletados. Notou-se no referido estudo que as percepções dos moradores da Engomadeira sobre a Uneb diferem pelo nível de escolaridade, em que os moradores de nível fundamental e médio percebem a universidade com relações positivas e os de nível superior com relações negativas.
\end{abstract}

Palavras-chaves: Comunidade; Instituição de ensino; Presença; Educação.

\section{Perceptions of the Residents of the Engomadeira Neighborbood on the UNEB-BA}

\begin{abstract}
This work aims to analyze the perceptions of residents of Bairro Engomadeira about the State University of Bahia (UNEB), Campus I, Salvador, to propose improvements in the relations established between the Community and the University. For the discussion, authors such as Fialho (1998), Midlej (2004) and Santos (2014) were consulted. The research was developed in a qualitative approach, using semi-structured interviews and closed questionnaires as a data collection instrument, applied to a non-probabilistic sample of 20 (twenty) residents, dividing into three groups, by level of education: elementary level, medium level and higher level, to identify and analyze their perceptions. Content analysis by Bardin (2002) was used, and in the light of authors such as Midlej (2004) and Santos (2008), for the treatment of the collected data. It was noted in that study, that the perceptions of the residents of the Ironing Company about Uneb differ by the level of education, where the residents of elementary and high school perceive the university with positive relationships and those with higher education, with negative relationships.
\end{abstract}

Keywords: Community; Educational institution; Presence; Education.

1 Instituto Federal de Educação, Ciência e Tecnologia Baiano - Santa Inês - Bahia - BA - Brasil; jose.ricardo@ifbaiano.edu.br

2 Instituto Federal de Educação, Ciência e Tecnologia Baiano - Santa Inês - Bahia - BA - Brasil; lsjeanne@hotmail.com

Universidade do Estado da Bahia - UNEB - Bahia - BA - Brasil; luisgluneb@yahoo.com.br

4 Universidade do Estado da Bahia - UNEB - Bahia - BA - Brasil; nabom_reis@hotmail.com 


\section{Las Percepciones de los Habitantes del barrio de Engomadeira sobre UNEB-BA}

\section{Resumen}

Este trabajo tiene como objetivo analizar las percepciones de los habitantes del Barrio Engomadeira sobre la Universidad Estatal de Bahía (UNEB), Campus I, Salvador, con el fin de proponer mejoras en las relaciones establecidas entre la Comunidad y la Universidad. Para la discusión se utilizaron autores como Fialho (1998), Midlej (2004) y Santos (2014). La investigación se desarrolló con un enfoque cualitativo, utilizando entrevistas semi-estructuradas y cuestionarios cerrados como instrumento de recolección de datos, aplicados a una muestra no probabilística de 20 (veinte) residentes, divididos en tres grupos, por nivel de educación: nivel básico, nivel medio y nivel superior, para identificar y analizar sus percepciones. Se utilizó el análisis de contenido de Bardin (2002), ya la luz de autores como Midlej (2004) y Santos (2008), para el tratamiento de los datos recolectados. Se constató en dicho estudio, que las percepciones de los vecinos de la Empresa de Planchado sobre la Uneb difieren por el nivel de educación, donde los residentes de primaria y secundaria perciben la universidad con relaciones positivas y los de educación superior, con relaciones negativas.

Palabras clave: Comunidad; Institución educativa; Presencia; Educación.

\section{Introdução}

Pode-se considerar, em muitos aspectos, que a presença de uma universidade pública em determinada localidade caracteriza um processo de desenvolvimento econômico e social, o que pode se transfigurar na melhoria de vida das pessoas. A abundância de pesquisas realizadas nessas instituições contribui para a autonomia e o crescimento da região, o que cria a possibilidade de ampliação no desenvolvimento científico e tecnológico.

A presença da universidade pública é importante não só pela função social e econômica que exerce, é também fonte de conhecimento, de cultura e de compreensão política. Encontram-se, nela, os pensamentos que são a origem das transformações e os mecanismos necessários para sua execução. (Santos, 2014, p. 33).

A Universidade do Estado da Bahia (UNEB) possui condições de trabalhar em seu entorno e contribuir para o desenvolvimento sustentável dessas áreas através de projetos e ações, além de estender sua prática de ensino para fora dos limites da instituição, com a transmissão do conhecimento de forma integrada e integradora. O programa de Pós-Graduação em Educação e Contemporaneidadevem desenvolvendo ações voltadas à interação da instituição com a comunidade da Engomadeira, em especial os trabalhos ligados à Linha de Pesquisa Educação, Gestão e Desenvolvimento Local Sustentável.

Com toda essa potencialidade em criar alternativas de melhorias das condições de vida dos moradores do seu entorno, surgem inquietações, como: quais as "visões" e as possíveis "utilidades" (no sentido de contribuições) que os moradores têm sobre a universidade? Há afinidade de entendimento universidade e comunidade? Onde as percepções desses sujeitos se encontram com as concepções acadêmicas e epistemológicas discutidas no âmbito da Uneb?

Observando um dos contextos em que a comunidade da Engomadeira está inserida, a presença da Uneb torna-se, no seu espaço "agência" de produção, socialização e integração de conhecimentos. A relação entre a Universidade e as comunidades em seu entorno nem sempre é pautada de forma harmônica e inclusiva. Na maioria das vezes há um distanciamento e um certo desconhecimento de ambas as partes, principalmente se a universidade estiver localizada em áreas periféricas das cidades e se em seu entorno surgirem comunidades "carentes". Por seu caráter elitista, historicamente construído, o mundo acadêmico permaneceu longe da realidade local e quando a enxergava, era como "objeto" de pesquisa a ser analisado com toda neutralidade positivista possível, sem maiores envolvimentos ou ligação. Conforme destaca Santos (2014, p. 26),

A falta de projetos realizados com base em fundamentos éticos e científicos pode levar ao desenvolvimento de práticas mais fáceis e prejudiciais como a utilização das comunidades, apenas, para pesquisas com fins à obtenção de títulos. Esse tipo de ação leva a instituição a cair no descrédito, desgastando sua relação com a população e inviabilizando a função universitária na promoção do retorno social dos resultados das pesquisas realizadas $[\ldots]$ (Santos, 2014, p. 26). 
Nesse contexto, verifica-se um sentimento de "inferiorização" e distanciamento das comunidades diante das universidades, afastando-se do caráter de pertencimento e dificultando um maior envolvimento comunidade-universidade.

Fialho (1998, p. 28) advoga que "a universidade não pode compreender-se alheia aos variados fenômenos regionais e urbanos, nas suas mais diversificadas dimensões históricas, antropológicas, demográficas, educacionais, econômicas, culturais, etc.", o que demanda outra concepção de universidade, que seja plural, inclusiva, socialmente referenciada e aberta às demandas locais de produção e socialização de conhecimentos. Segundo a autora (Fialho, 1998, p. 27), "a universidade reúne, na sua própria condição de instituição promotora do avanço da ciência, a sua corresponsabilidade pela construção de perspectivas econômicas menos perversas e de relações sociais mais saudáveis".

Conforme destaca Bosi (1998, p. 14), “(..) a existência de uma boa universidade pública basta muitas vezes para transfigurar a vida de uma cidade. Através do conhecimento que produz e das pessoas que forma, ela irá colaborar ativamente para o progresso material, a melhoria da qualidade de vida e o ambiente cultural. Através das políticas públicas de Estado, as universidades têm possibilidades de trabalhar com suas áreas de abrangência, não caracterizando essas instituições como fazedoras do papel do Governo, mas como alternativas de extensão de políticas que venham a levar benefício à comunidade, utilizando-se das trocas de saberes, das pesquisas e dos programas e projetos institucionais ou encaminhados pelo governo.

\section{Método}

\section{Participantes}

As pessoas entrevistadas da engomadeira foram escolhidas com base em informações passadas pelos próprios moradores do bairro, seguindo alguns critérios básicos como perfil de liderança, envolvimento/contato com a universidade e tempo de residência

\section{Instrumento de coleta dedados}

Os entrevistados receberam o termo de consentimento livre e esclarecido (TCLE) e assinaram autorização como participante voluntário da pesquisa. Utilizou-se ainda o questionário para traçar o perfil dos (as) entrevistados (as).

A entrevista semiestruturada foi utilizada, por ter maior flexibilidade na condução do processo e amplia-se a possibilidade de se obter informações mais concretas na fala dos sujeitos entrevistados. Segundo Manzini (2004, p. 6), este tipo de entrevista possibilita “(...) fazer outras perguntas na tentativa de compreender a informação que está sendo dada ou mesmo a possibilidade de indagar sobre questões momentâneas à entrevista, que parecem ter relevância para aquilo que está sendo estudado.

Realizou-se um total de 20 (vinte) entrevistas, com moradores da Engomadeira, divididos em 3 (três) categorias: moradores com ensino fundamental, moradores com ensino médio e moradores com ensino superior, com um tempo mínimo de 8 (oito) anos de residência no local. Questionou-se sobre a contribuição da universidade para a localidade, qual a importância da instituição para eles, quais atividades são executadas pelos moradores no âmbito do campus e como é a relação entre eles (universidade - comunidade).

\section{Local}

Bairro Engomadeira (Figura 1). A Engomadeira representa um bairro de exclusão socio-territorial e carente da cidade de Salvador, com construções desorganizadas, infraestrutura deficiente e presença de violência urbana. Sua divisa territorial com a Uneb está demarcada por muros que a separa, mas ao mesmo tempo possibilita "contatos" e passagens, o que mantém uma relação direta com a universidade. Sobre a Engomadeira, Correia (2016, p. 64-65) destaca:

De origem popular, povoado e desordenadamente urbanizado, a Engomadeira concentra problemas característicos e comumente presentes nas grandes cidades brasileiras, como a falta de direitos básicos essenciais a exemplo de: saneamento precário, praças, parques, centros culturais e esportivos, além de ser um bairro onde vive grande maioria de pessoas desfavorecidas economicamente, com indicadores de pobreza, desemprego, violência, drogas, entre outros. (Correia, 2016, p. 64-65) 


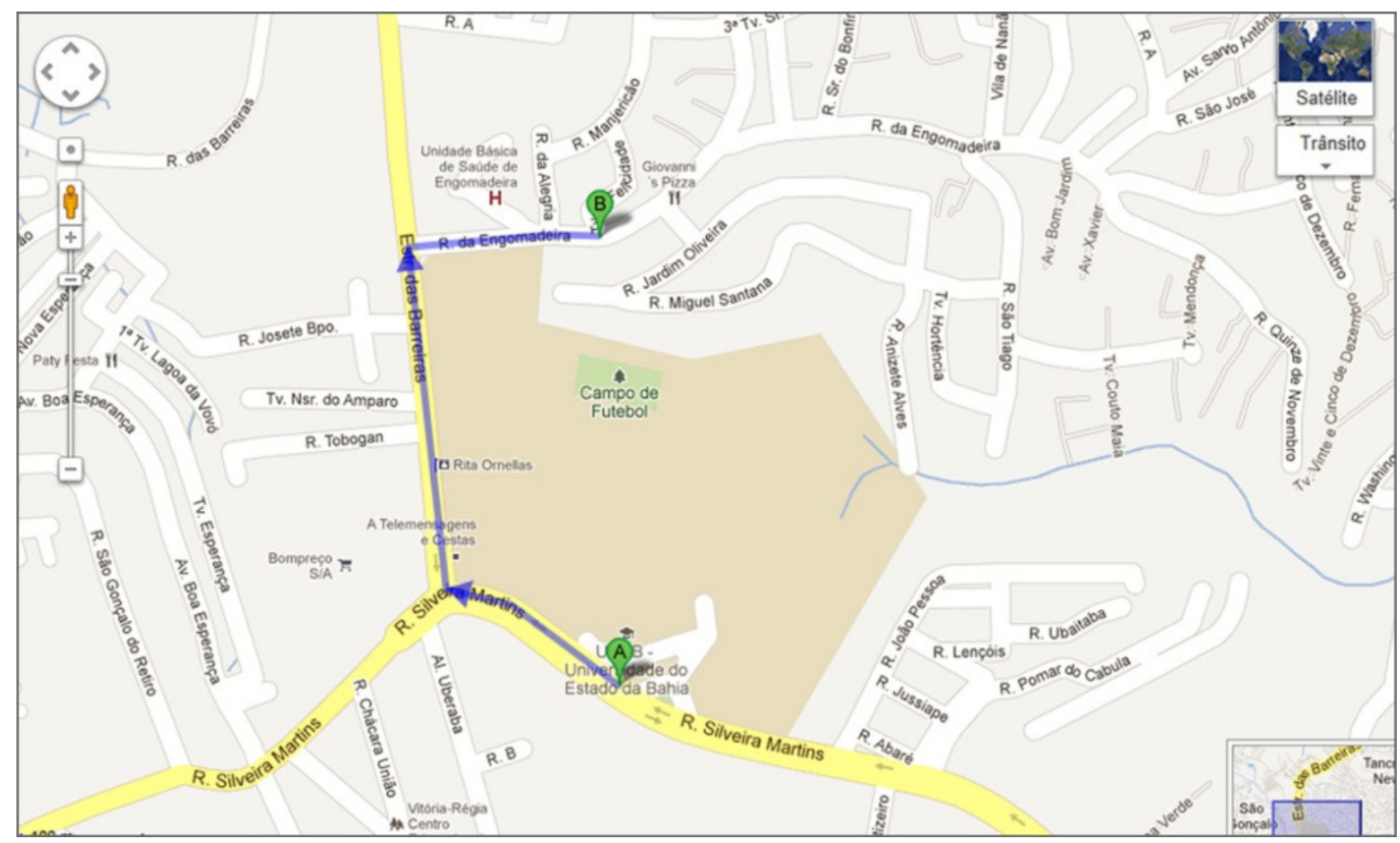

Fonte: Google Maps, 2014.

Figura 1. Bairro da Engomadeira

\section{Materiais}

Questionários, gravador e máquina fotográfica.

\section{Procedimentos}

Etapa 1 - Organização e embasamento teórico

Buscando resguardar os nomes dos entrevistados nas citações desse artigo, suas identificações estarão apresentadas de forma codificada: Nível Fundamental: F1, F2, F3, F4 e F5; Nível Médio: M1, M2, M3, M4, M5, M6, M7, M8 e M9, e, Nível Superior: S1, S2, S3, S4, S5 e S6.

Após as anotações e transcrições efetuadas por meio do Microsoft Word 2011, utilizaram-se tabelas para exposição das análises da pesquisa. Trabalhou-se com pesquisa bibliográfica, com consulta em bibliotecas, pessoais e públicas, e por meio eletrônico. As respostas dos sujeitos da pesquisa foram analisadas por meio da técnica de análise de conteúdo, fundamentada por Bardin (2000), Midlej (2004) e Santos (2008).

\section{Etapa 2 - Identificação das palavras-chave, ocorrências} e co-ocorrências

As palavras-chave foram percebidas através da identificação da maior frequência das palavras e serviram para guiar o processo de identificação das co-ocorrências e das relações positivas (associações) e negativas (oposições). Os termos semânticos e os conectivos não foram considerados. As co-ocorrências e as relações foram retiradas a partir das unidades de análise (frases) apresentadas pelas palavras com maior frequência. Foram utilizadas tabelas de análise, com base nos trabalhos de Santos (2008) e Midlej (2004). Após leitura rigorosa de todas as respostas, estas foram articuladas com o referencial teórico.

As palavras-chave serviram de orientação para a identificação das co-ocorrências e consequentemente das relações estabelecidas entre elas. Para Midlej (2004, p. 170), "as palavras-chave, funcionando como indicadores dos elementos básicos que compõem o quadro de referência do estudo desempenham papel de baliza do texto". É importante ressaltar que as palavras-chave foram identificadas após processo minucioso de seleção e com base no quantitativo das falas ou respostas escritas. 
Etapa 3 - Análise e interpretação dos dados

Para análise e discussão dos resultados, selecionaram-se as palavras-chave e identificaram-se as co-ocorrências, apresentando as relações positivas (associações) e as relações negativas (oposições). Para melhor visualização das palavras de maior frequência apresentadas nas entrevistas, utilizou-se uma nuvem de palavras (Figura 2).

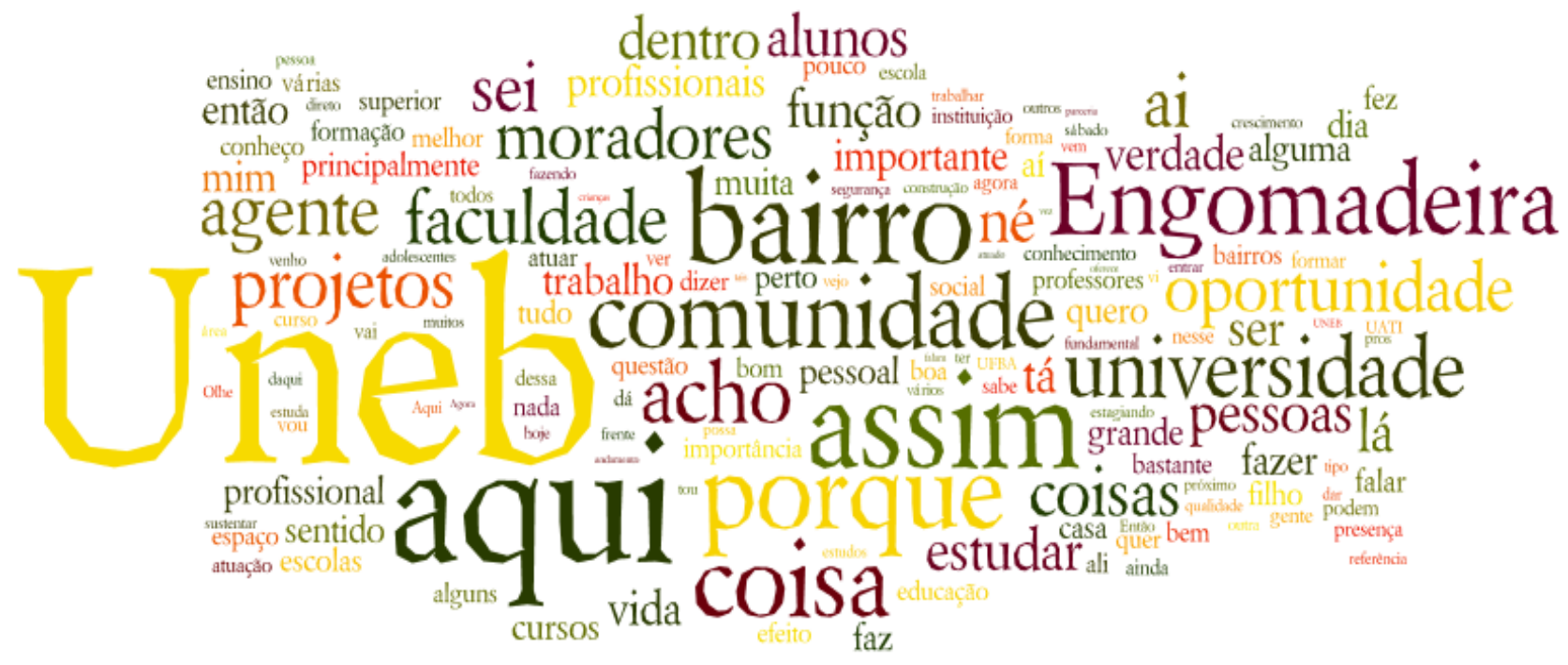

Fonte: Elaborado pelos autores.

Figura 2. Nuvem de palavras Representações UNEB

Apresentaram-se tabelas com as palavras-chave, as co-ocorrências e as relações. As palavras-chave foram escritas em formato negrito e maiúsculo, as co-ocorrências em negrito e as relações, sublinhadas. Através dessas tabelas, identificaram-se na comunidade da Engomadeira, nos níveis fundamental, médio e superior, as percepções dos moradores da Engomadeira sobre a Uneb, com suas respectivas associações e oposições.

\section{Resultados}

As palavras-chave encontradas após a análise de maior potência e frequência nas entrevistas foram: UNEB, BAIRRO E COISA.

Para os moradores da Engomadeira com nível de formação fundamental, as co-ocorrências mais frequentes em relação à palavra-chave UNEB foram: coisa e filho. Para os moradores com formação em nível médio: bairro, universidade/faculdade e coisa. Já os moradores com formação em nível superior foram: bairro, comunidade e aluno.

Observa-se que, enquanto os moradores de nível fundamental e médio percebem relações positivas à palavra-chave UNEB em relação às suas co-ocorrências, os moradores de nível superior percebem relações negativas.

Os moradores com formação em ensino fundamental associam à palavra-chave UNEB, apresentando que nesta relação entre universidade e comunidade acontecem coisas que nem se espera acontecer, principalmente para os adolescentes, e deixam claro que a instituição presta um serviço importante. Para Bomfim (2009, p. 69) "O território pode ser traduzido, como o espaço onde as pessoas estabelecem relações afetivas e subjetivas, em lugar de relações racionais e objetivas"

Oh, show! Aqui a gente tem tudo, tamos perto de casa, um pulo eu tou dentro da Uneb, já pensou se eu trabalhasse longe de casa, eu tou aqui na Uneb, me sinto em casa porque eu passo a maior parte da minha vida dentro da Uneb, eu só vou pra casa a tarde, então aqui pra mim a Uneb é show de bola em tudo, em tudo que eu conseguir, eu tenho que agradecer a Uneb, tudo sem tirar e sem colocar, tudo! (F5)

Os moradores com nível médio também têm identificação positiva referente à relação Uneb e comunidade. Segundo eles, a universidade é útil em várias 
coisas que ainda não 'temos' no bairro (grifo nosso). Sua presença é muito importante e tem um espaço muito bom para as atividades de lazer e socialização. Para eles, a Uneb tem como função ajudar a comunidade, é útil em várias coisas e, por ser uma universidade pública, pode representar até o país. Eles destacam que nela tem oportunidade de entrar e estudar e nem precisa fazer esforço para deslocamento.

Segundo Parazelli (2002, apud BOMFIM, 2009, p. 24) " [...] um sentimento de pertencimento se desenvolve e se localiza numa rede de lugares valorizados, de acordo com o seu valor simbólico e seu potencial identitário"

A Uneb é muito importante para todos nós porque eu acho que temos oportunidade de entrar na faculdade e estudar. Sei que tem várias coisas para a gente e sei também que com tudo mais fácil vai ser bom estudar mesmo porque sem estudo não somos nada nesse país. (M2)

A Uneb é um lugar no estado que atua com o objetivo de alcançar as famílias de baixa renda e forma profissionais em várias áreas no mercado de trabalho. (M3)

Pra ser sincero a você é bom porque é uma referência, ela é uma referência. Uma faculdade estadual, é muito mais fácil você vai dar uma referência, porque muitos lugares a gente chega assim e fala assim "moro na Engomadeira” e tem pessoas que não sabe, aí a gente dá a referência que é a Uneb, aí o pessoal sabe onde é. (M8)

Os moradores com nível superior têm na representação sobre a Uneb relações negativas. Para eles, existe uma expectativa muito grande sobre a universidade, porém, há distanciamento de fato. Não tem atuado como deveria e, em vez de trabalhar a comunidade, tem atuado em bairros distantes. Destacam também que não veem alunos da Uneb no bairro e não conhecem nenhum trabalho de extensão.

A Uneb deveria proporcionar mais projetos socioeducativos para a comunidade, pois quando as mesmas acontecem ficam restritas ao espaço acadêmico. (S4)

Nada. Ah sim, tem oferecido alguns serviços na área de saúde, a gente tem o fonoaudiólogo aqui, a gente tem a questão dos nutricionistas, tem a questão de algumas atividades que é aberta para a comunidade, mas, assim, no sentido acadêmico mesmo, a Uneb não tem atuado na comunidade não, não tem desenvolvido pesquisa que surta efeito direto não. $\mathrm{Na}$ verdade, a comunidade ocupa esse espaço aqui, mas com questões externas, tipo projetos externos e não projetos acadêmicos. (S5)

Poxa! Atualmente não conheço nenhum trabalho de extensão da Uneb que se aplique no bairro não, a não ser a proposta da construção de uma base militar de segurança, que eles dizem que é de segurança e que na verdade a comunidade não foi consultada, nem apoia esse tipo de iniciativa. (S6)

Essa representação social precisa ser trabalhada pela universidade, pois, segundo Bomfim (2009, p. 64), "os espaços estão presentes nas representações das pessoas e constituem uma matriz da experiência social, uma mediação entre a experiência vivida e as representações construídas por elas". Sendo assim, quanto mais próxima a Uneb estiver da comunidade da Engomadeira, maior sua percepção como instituição pertencente ao lugar social. (Tabelas 1, 2, 3). 


\section{Tabela 1}

Co-ocorrências e Relações dos moradores da Engomadeira com formação ensino médio associadas a palavra-chave UNEB.

\begin{tabular}{|c|c|c|c|c|}
\hline \multirow[b]{2}{*}{ Co-ocorrência } & \multicolumn{4}{|c|}{ RELAÇÕES } \\
\hline & $\begin{array}{l}\text { Relações positivas } \\
\text { Associações }\end{array}$ & $\mathrm{n} .^{\circ}$ & $\begin{array}{l}\text { Relações negativas } \\
\text { Oposições }\end{array}$ & n. ${ }^{\circ}$ \\
\hline \multirow{4}{*}{ Bairro } & Presença muito importante & 1 & & \\
\hline & Presença fundamental & 1 & & \\
\hline & Espaço muito bom & 1 & & \\
\hline & $\begin{array}{c}\text { Útil em várias coisas que ainda não } \\
\text { temos no bairro }\end{array}$ & 1 & & \\
\hline \multirow{5}{*}{ Universidade/Faculdade } & Temos uma universidade & 1 & & \\
\hline & Representar até o país & 1 & & \\
\hline & $\begin{array}{c}\text { Nem precisa fazer esforço para } \\
\text { deslocamento }\end{array}$ & 2 & & \\
\hline & Oportunidade de entrar e estudar & 1 & & \\
\hline & É uma universidade pública & 1 & & \\
\hline \multirow{4}{*}{ Coisas } & Faz um curso & 1 & Agora é que não tem mais & 1 \\
\hline & Conheço muitas coisas boas & 2 & & \\
\hline & Ajudar a comunidade & 1 & & \\
\hline & Útil em várias coisas & 1 & & \\
\hline TOTAL & & 15 & & 1 \\
\hline
\end{tabular}

Fonte: Elaborada pelos autores (2014).

\section{Tabela 2}

Co-ocorrências e Relações dos moradores da Engomadeira com formação superior associadas a palavra-chave UNEB.

\begin{tabular}{|c|c|c|c|c|}
\hline \multirow[b]{2}{*}{ Co-ocorrência } & \multicolumn{4}{|c|}{ RELAÇÕES } \\
\hline & $\begin{array}{c}\text { Relações positivas } \\
\text { Associações }\end{array}$ & n. ${ }^{\circ}$ & $\begin{array}{l}\text { Relações negativas } \\
\text { Oposições }\end{array}$ & n. ${ }^{\circ}$ \\
\hline \multirow{5}{*}{ Bairro } & & & $\begin{array}{c}\text { Não conheço nenhum trabalho de } \\
\text { extensão }\end{array}$ & 1 \\
\hline & & & Criou-se expectativa muito grande & 2 \\
\hline & & & Tem atuado em bairros distantes & 1 \\
\hline & & & Não vê alunos da UNEB & 1 \\
\hline & & & Há distanciamento de fato & 1 \\
\hline \multirow{3}{*}{ Comunidade } & $\begin{array}{l}\text { Contribuído para o desenvolvimento } \\
\text { individual }\end{array}$ & 1 & Deveria propiciar mais projetos & 1 \\
\hline & & & Não tem atuado & 1 \\
\hline & & & Não ver alunos atuando & 1 \\
\hline Alunos & Alunos cotistas & 1 & A gente não vê alunos da UNEB aqui & 2 \\
\hline TOTAL & & 2 & & 11 \\
\hline
\end{tabular}

Fonte: Elaborada pelos autores (2014). 


\section{Tabela 3}

Co-ocorrências e Relações dos moradores da Engomadeira com formação em Ensino Fundamental associadas a palavra-chave BAIRRO.

\begin{tabular}{lcccc}
\hline \multirow{2}{*}{ Co-ocorrência } & \multicolumn{4}{c}{ RELAÇÕES } \\
\cline { 2 - 5 } & $\begin{array}{c}\text { Relações positivas } \\
\text { Associações }\end{array}$ & $\mathrm{n} .^{\circ}$ & $\begin{array}{c}\text { Relações negativas } \\
\text { Oposições }\end{array}$ & $\mathbf{n} .^{\circ}$ \\
\hline Coisas & $\begin{array}{c}\text { Pessoas idosas se sentem bem } \\
\text { UNEB }\end{array}$ & 1 & & \\
\hline TOTAL & Trabalho muito importante & 1 & 2 & 0 \\
\hline
\end{tabular}

Fonte: Elaborada pelos autores (2014).

No que concerne à palavra-chave BAIRRO, os moradores com nível de formação em ensino fundamental apresentam as co-ocorrênciaas: coisas e UNEB. Para os moradores com formação em nível médio: Engomadeira e faculdade. Os moradores com formação em nível superior foram: bairro, comunidade e aluno. (Tabelas 4, 5 e 6).

\section{Tabela 4}

Co-ocorrências e Relações dos moradores da Engomadeira com formação em Ensino Médio associadas a palavra-chave BAIRRO.

\begin{tabular}{|c|c|c|c|c|}
\hline \multirow[b]{2}{*}{ Co-ocorrência } & \multicolumn{4}{|c|}{ RELAÇÕES } \\
\hline & $\begin{array}{c}\text { Relações positivas } \\
\text { Associações }\end{array}$ & n. ${ }^{\circ}$ & $\begin{array}{c}\text { Relações negativas } \\
\text { Oposições }\end{array}$ & n. ${ }^{\circ}$ \\
\hline \multirow[b]{2}{*}{ Engomadeira } & Papel muito grande & 1 & Poderia atribuir mais projetos & 1 \\
\hline & $\begin{array}{l}\text { Ta virando centro de grande } \\
\text { comércio }\end{array}$ & 1 & $\begin{array}{c}\text { Deveria levar seus olhos um } \\
\text { pouquinho mais }\end{array}$ & 1 \\
\hline \multirow{3}{*}{ Faculdade } & Dá até segurança & 1 & & \\
\hline & Acolhe os alunos & 1 & & \\
\hline & $\begin{array}{l}\text { É cômodo morar perto de uma } \\
\text { faculdade }\end{array}$ & 1 & & \\
\hline TOTAL & & 5 & & 2 \\
\hline
\end{tabular}

Fonte: Elaborada pelos autores (2014).

\section{Tabela 5}

Co-ocorrências e Relações dos moradores da Engomadeira com formação Superior associadas a palavra-chave BAIRRO.

\begin{tabular}{|c|c|c|c|c|}
\hline \multirow[b]{2}{*}{ Co-ocorrência } & \multicolumn{4}{|c|}{ RELAÇÕES } \\
\hline & $\begin{array}{c}\text { Relações positivas } \\
\text { Associações }\end{array}$ & n. ${ }^{\circ}$ & $\begin{array}{c}\text { Relações negativas } \\
\text { Oposições }\end{array}$ & n. ${ }^{\circ}$ \\
\hline Comunidade & & & São decepcionados & 2 \\
\hline \multirow{2}{*}{ Moradores } & & & Pensavam que ia surtir efeito & 1 \\
\hline & & & Esperavam uma atuação melhor & 1 \\
\hline TOTAL & & 0 & & 4 \\
\hline
\end{tabular}

Fonte: Elaborada pelos autores (2014). 


\section{Tabela 6}

Co-ocorrências e Relações dos moradores da Engomadeira com formação fundamental associadas a palavra-chave COISA.

\begin{tabular}{ccccc}
\hline \multirow{2}{*}{ Co-ocorrência } & \multicolumn{3}{c}{ RELAÇÕES } \\
\cline { 2 - 5 } & $\begin{array}{c}\text { Relações positivas } \\
\text { (Associações) }\end{array}$ & n. & $\begin{array}{c}\text { Relações negativas } \\
\text { Oposições }\end{array}$ & n. $^{\circ}$ \\
\hline UNEB & Coisas da UNEB & 2 & Começou e não terminou & 1 \\
Faz & Faz muita coisa & 4 & Falta na UNEB & 2 \\
Brigar & & 6 & & 3 \\
\hline TOTAL & & & & \\
\hline
\end{tabular}

Fonte: Elaborada pelos autores (2014).

Observa-se que mais uma vez que enquanto os moradores de nível fundamental e médio percebem relações positivas à palavra-chave BAIRRO em relação às suas co-ocorrências, os moradores de nível superior percebem relações negativas.

Segundo os moradores de nível fundamental e médio, as pessoas idosas se sentem bem na Uneb, que faz um trabalho muito importante. Declaram também que é cômodo morar perto de uma faculdade, devido às facilidades de acesso e referência residencial. Além disso, morar perto de uma universidade dá até segurança. Eles percebem a possibilidade de desenvolvimento local ao afirmar que o bairro, devido a presença da universidade, está virando centro de grande comércio.
Quanto aos moradores de nível superior, estão e são decepcionados com a presença da Uneb, pois pensavam que ia surtir efeito positivo para a comunidade a existência de uma relação direta com a instituição. Eles esperavam uma atuação melhor da Uneb para intervir e melhorar as condições de vida dos moradores da Engomadeira.

Quanto à palavra-chave COISA, os moradores com nível de formação fundamental, apresentam as co-ocorrências: UNEB, Faz e Brigar. Para os moradores com formação em nível médio: A gente e bairro. Os moradores com formação em nível superior não apresentam co-ocorrências. (Tabelas 7 e 8).

\section{Tabela 7}

Co-ocorrências e Relações dos moradores da Engomadeira com formação em ensino médio associadas a palavra-chave COISA.

\begin{tabular}{|c|c|c|c|c|}
\hline \multirow[b]{2}{*}{ Co-ocorrência } & \multicolumn{4}{|c|}{ RELAÇÕES } \\
\hline & $\begin{array}{c}\text { Relações positivas } \\
\text { Associações } \\
\end{array}$ & n. ${ }^{\circ}$ & $\begin{array}{c}\text { Relações positivas } \\
\text { Oposições }\end{array}$ & n. ${ }^{\circ}$ \\
\hline \multirow{3}{*}{ A gente } & Tem várias coisas para a gente & 1 & A gente espera mais & 1 \\
\hline & Conhecimento para ter oportunidade & 1 & Não é parceria forte & 1 \\
\hline & & & O pessoal ainda é muito arredio & 1 \\
\hline \multirow{2}{*}{ Bairro } & Já fez várias coisas & 1 & Cabe a ela incentivar mais projetos & 1 \\
\hline & & & Que venha acontecer mais coisas & 1 \\
\hline TOTAL & & 3 & & 5 \\
\hline
\end{tabular}

Fonte: Elaborada pelos autores. 


\section{Tabela 8}

Co-ocorrências e Relações dos moradores da Engomadeira com formação em ensino médio associadas a palavra-chave COISA.

\begin{tabular}{lcccc}
\hline \multirow{2}{*}{ Co-ocorrência } & \multicolumn{4}{c}{ RELAÇÕES } \\
\cline { 2 - 6 } & $\begin{array}{c}\text { Relações positivas } \\
\text { Associações }\end{array}$ & n. & $\begin{array}{c}\text { Relações positivas } \\
\text { Oposições }\end{array}$ & n. $^{\circ}$ \\
\hline \multirow{2}{*}{ A gente } & $\begin{array}{c}\text { Tem várias coisas para a gente } \\
\text { Conhecimento para ter oportunidade }\end{array}$ & 1 & $\begin{array}{c}\text { A gente espera mais } \\
\text { Não é parceria forte } \\
\text { O pessoal ainda é muito arredio }\end{array}$ & 1 \\
\hline Bairro & Já fez várias coisas & 1 & Cabe a ela incentivar mais projetos & 1 \\
& & & Que venha acontecer mais coisas & 1 \\
\hline TOTAL & 3 & & 5 \\
\hline
\end{tabular}

Fonte: Elaborada pelos autores.

Enquanto os moradores de nível fundamental percebem relações positivas à palavra-chave COISA em relação às suas co-ocorrências, os moradores de nível médio percebem relações negativas.

Para os moradores de nível fundamental, existem em prol da comunidade coisas da Uneb, porém fazem uma crítica aos projetos que iniciam e não findam. Segundo eles, a Uneb faz muita coisa, tanto no âmbito da pesquisa, do ensino e, principalmente, relacionados à extensão.

Para o nível médio, apesar da Uneb ter várias “coisas" para Engomadeira, ela não é parceria forte. A comunidade sempre espera mais da instituição, porém, como o pessoal é muito distante, não há aproximação nem de um lado nem de outro. Acreditam que cabe à Uneb, incentivar mais projetos.

Ela faz assim pela comunidade, (...) na verdade ela já fez várias coisas, só que o BAIRRO é ainda assim muito, como posso dizer assim?, (...) não é uma parceria forte, na verdade as pessoas quer que as coisas aconteçam, mas vem acontecendo bem lento, a gente (...) na verdade quando a gente fecha assim direitinho, o pessoal não chega, a verdade é essa, a gente até que quer somar alguma coisa, mas o pessoal ainda é muito arredio. (M6)

Em resumo, como respostas às perguntas da pesquisa, percebe-se na fala dos moradores da Engomadeira que a relação Uneb-comunidade é tranquila, porém, que a instituição tem potencial para contribuir muito mais no processo de desenvolvimento socioeconômico da comunidade:

1. Contribuição da universidade para a localidade: A presença da Uneb na Engomadeira contribui para a formação acadêmica e profissional dos jovens, acolhe as pessoas idosas com projetos sociais, desenvolve o comércio local e é um espaço público com acesso à comunidade

2. Importância da instituição: A Uneb contribui para a inclusão social, serve como referência local e ajuda a comunidade com acesso aos projetos da instituição. Além disso, valoriza o bairro e facilita o acesso a serviços para a comunidade.

3. Atividades executadas pelos moradores no âmbito com campus: Muitas atividades são executadas, tendo em vista os projetos de ensino, de pesquisa e de extensão que têm na Engomadeira uma possibilidade próxima e com histórico de envolvimento com a instituição. A relação é tranquila, porém existe uma cobrança para que haja mais atuação da instituição na localidade

\section{Discussão}

Percebe-se nas relações entre os sujeitos da pesquisa uma ligação de forma opositora, em que, no decorrer do tempo e das percepções de ambas as partes, essas relações podem se modificar e estabelecer a ampliação das pesquisas e dos debates sobre a temática. Só assim os moradores das comunidades do entorno das universidades desenvolverão o sentimento de pertencimento, pois, segundo Bomfim (2009 p. 64), "essa relação entre o indivíduo e o espaço se articula entre duas dimensões interdependentes: a espacialidade das estruturas sociais e a sociabilidade das estruturas espaciais", onde a universidade se "mescla" se "imbui" se "envolve" com os problemas locais tornando-se parte da comunidade e os moradores das comunidades se envolvem no dia a dia 
da universidade, sendo sujeitos ativos e demandantes de seus serviços, pois, para Santos (2014):

a presença da universidade pública é importante não só pela função social e econômica que exerce, é também fonte de conhecimento, de cultura e de compreensão política. Encontram-se, nela, os pensamentos que são origens das transformações e os mecanismos necessários para sua execução. (Santos, 2014, p. 33)

Como as atividades fins das universidades são bem diferentes do que as comunidades estão acostumadas a perceber de órgãos públicos, surgem entendimentos e concepções distantes da realidade e possibilidade da Uneb.

Há, no mínimo, uma relação de vizinhança entre a Uneb e o bairro da Engomadeira e seus moradores têm contatos permanentes com a universidade, seja abrigando estudantes que ali passam a residir, seja como local de lazer (caminhadas diárias), de cuidados com os pássaros cativos, de acesso aos serviços de atendimento à saúde (médicos, nutricionistas, psicólogos etc.), de local de trabalho e até mesmo como "atalho" para encurtar o percurso para suas residências.

\section{Considerações finais}

A partir deste estudo verificou-se que as percepções dos moradores da Engomadeira sobre a Uneb, apresentam elementos que envolvem atitudes positivas quanto à presença da instituição. No que concerne aos moradores de nível superior, constatam-se representações opositivas.

Com base nessa observação e nas constatações presentes nas entrevistas, mostra-se que se faz necessário ter uma aproximação maior e mais eficaz da instituição no contexto da Engomadeira, não somente através da sua ação institucional fria de ensino, pesquisa e extensão. Torna-se cada vez mais necessário que a comunidade perceba a Uneb como parte integrante, integrada e pertencente ao local.

Como a percepção dos moradores de nível superior é negativa, deve-se também buscar alternativas para se atingir esse grupo social, de forma a atrair e construir mais apoiadores e incentivadores da constituição de um contexto em que Uneb e Engomadeira não sejam dois pontos distantes e divergentes. Que haja a harmonia nas ações e que a missão da instituição transcenda suas atribuições formais. Que a comunidade da Engomadeira sinta na Uneb um órgão parceiro para o desenvolvimento socioeconômico local.

Faz-se necessário definir metas de curto, médio e longo prazo, com base em projetos de pesquisa e extensão já existentes, bem como a ampliação da atuação universitária em todas as áreas de conhecimentos que são desenvolvidas na instituição.

\section{Referências}

Bardin, L. (2002). Análise de conteúdo. Tradução Luís Antero Reto e Augusto Pinheiro. Lisboa (Portugal): Ed. 70.

Bomfim, N. R. (2009). Noção social do território: em busca de um conceito didático em geografia - a territorialidade. Ilhéus: Editus.

Bosi, A. (coord.). (1998). A presença da universidade pública. São Paulo, Recuperado de: http://www.fisica.uel.br/ SBPC_LD/unipub.html. Acesso em: 14 jul. 2006.

Correia, S. L. C. P. (2016). Entre ruas e ladeiras, Engomadeira sou eu!. Representações sócio espaciais e professores sobre o bairro. Salvador, Dissertação de mestrado, Universidade do Estado da Bahia, Programa de Pós - Graduação em Educação e Contemporaneidade, Bahia, Brasil.

Fialho, Nadia Hage. (1998). A Missão da universidade. Revista da FAEEBA, 7(10), 25-42.

Lopes, R. P. M. (2003). Universidade Pública e Desenvolvimento Local: Uma Abordagem a Partir dos Gastos da Universidade Estadual do Sudoeste da Bahia. Vitória da Conquista: Edições UESB.

Midlej, M. M. B. C. (2004). Universidade e região: territorialidade da Universidade Estadual de Santa Cruz UESC. Salvador. Tese de doutorado, Universidade do Federal da Bahia, Faculdade de Educação, Programa de Pós Graduação em Educação, Bahia, Brasil.

Santos, J. R. R. (2008). Universidade pública e desenvolvimento local: a presença da Universidade Estadual de Santa Cruz (UESC) no bairro do Salobrinho em Ilhéus Babia no período de 1991 a 2008. Dissertação de mestrado, Universidade do Estado da Bahia, Programa de Pós-Graduação em Políticas Públicas, Gestão do Conhecimento e Desenvolvimento Regional, Bahia, Brasil.

(2014). Universidade pública e desenvolvimento local: a presença da Universidade Estadual de Santa Cruz (UESC) no bairro do Salobrinho em Ilbéus Babia no período de 1991 a 2008. Ilhéus: Editus.

Recebido em: 10 Abr. 2018 Aprovado em: 27 Jul. 2021 